\title{
Um estudo sobre a inclusão de pessoas com deficiência no mercado de trabalho brasileiro
}

\author{
Marwin Machay Indio do Brasil do Carmo \\ Clarissa Garcia Gilla \\ Patricia Lorena Quiterio
}

\section{RESUMO}

O objetivo do presente artigo foi investigar o processo da inclusão das Pessoas Com Deficiência (PCD) no mercado de trabalho brasileiro averiguando: i) os motivos do envolvimento de empresas na contratação destas pessoas, ii) o perfil dos funcionários e o processo de contratação e, iii) sua rotina no cotidiano da empresa. Para isso, um questionário foi respondido por meio digital por quatro (4) empresas clientes de uma plataforma online de anúncio de vagas de emprego para PCD. As respostas apontaram que as justificativas para a contratação de PCD se referem ao cumprimento da cota exigida por lei de funcionários com deficiência. Constatou-se que nestas empresas os funcionários com deficiência ocupam uma parcela próxima a exigência mínima requerida pela lei. A análise de conteúdo indicou que esses dados refletem uma falta de confiança das empresas na capacidade produtiva das PCD. Conclui-se que o amparo legal por si só não é suficiente para a inclusão da PCD no mercado de trabalho, é preciso que as empresas se empenhem na promoção de ajustes ambientais e atitudinais em favor das PCD.

Palavras-chave: mercado de trabalho; pessoas com deficiência; inclusão social.

\section{ABSTRACT}

\section{A study about the inclusion of people with disabilities in the brazilian labour market}

The goal of the present article was to explore the inclusion process of people with disabilities (PWD) in the Brazilian labor market inquiring: i) the reasons for the involvement of business companies in hiring these people, ii) the employees' profile and the hiring process and iii) how is the daily routine of those employees in the work environment. To accomplish this, an interview script was answered via digital media by four (4) companies clients of an online job posting platform. The answers indicated that the reason for hiring PWD is the fulfillment of the minimum quota of employees with disabilities demanded by law. It was found that in these companies the employees with disabilities occupy a portion close to the minimum required by law. The content analysis indicated that these data reflect a lack of trust in the productive capacity of PWD. This article concludes that the legal support itself is not enough to the inclusion of the PWD in the labor market. It is necessary that companies focus in promoting environmental and attitudinal adjustments in favor of PWD.

Keywords: labor market; people with disabilities; social inclusion.

Segundo dados da Organização Mundial da Saúde disponibilizados no Relatório Mundial Sobre a Deficiência (OMS, 2011), estima-se que mais de um bilhão de pessoas, ou 15\% da população mundial, convivam com alguma forma de deficiência. 0 relatório ainda informa que, de acordo com o World Health Survey (World Health Organization, 2003), cerca de 785 milhões $(15,6 \%)$ de pessoas a partir dos 15 anos de idade apresenta alguma deficiência, enquanto o Global Burden of Disease (World Health Organization, 2008) estima que sejam 975 milhões $(19,4 \%)$. O World Health Survey (World Health Organization, 2003) avalia que, no mundo, 110

\section{Sobre os Autores}

M. M. I. B. C.

orcid.org/0000-0002-1052-6300 Universidade do Estado do Rio de Janeiro (UERJ) - Rio de Janeiro, RJ

marwinbr@gmail.com

\section{G. G}

orcid.org/0000-0002-3529-5510 Universidade do Estado do Rio

de Janeiro (UERJ) - Rio de

Janeiro, RJ

clarissagilla@yahoo.com.br

P. L. Q.

orcid.org/0000-0002-4553-6429

Universidade do Estado do Rio de Janeiro (UERJ) - Rio de Janeiro, RJ

patricialorenauerj@gmail.com

\section{Direitos Autorais}

Este é um artigo de acesso aberto e pode ser reproduzido livremente, distribuído,

transmitido ou modificado, por qualquer pessoa desde que usado sem fins comerciais. 0 trabalho é disponibilizado sob a licença Creative Commons CCBY-NC.

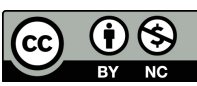


milhões de pessoas $(2,2 \%)$ possuem graus significativos de deficiências (permanente ou temporária), ao passo que, segundo a estimativa do Global Burden of Disease (World Health Organization, 2008), esses números sobem para 190 milhões (3,8\%). Conforme o artigo 1 da Convenção Interamericana para a Eliminação de Todas as Formas de Discriminação contra as Pessoas Portadoras de Deficiência (Decreto $n$. 3.956, 2001), o termo deficiência significa "uma restrição física, mental ou sensorial, de natureza permanente ou transitória, que limita a capacidade de exercer uma ou mais atividades essenciais da vida diária, causada ou agravada pelo ambiente econômico e social”.

O Relatório Mundial Sobre a Deficiência (OMS, 2011) destaca algumas das barreiras à plena inserção das Pessoas Com Deficiência (PCD) na sociedade:

a) Políticas e padrões inadequados: O planejamento das políticas nem sempre considera as necessidades das PCD, ou as existentes não são aplicadas.

b) Atitudes negativas: Atitudes preconceituosas formam barreiras para o acesso à educação, ao emprego, à assistência médica e à participação na sociedade. A inclusão escolar da criança com deficiência pode ser afetada por atitudes negativas de professores, escolas, outras crianças e da própria família. Empregadores com perspectivas equivocadas sobre a capacidade produtiva da pessoa com deficiência ser inferior à de pessoas com desenvolvimento típico e o desconhecimento dos possíveis ajustes ao espaço de trabalho restringem as oportunidades de emprego.

c) Falhas na oferta de serviços: PCD sofrem mais com a execução inadequada de serviços como assistência médica, reabilitação, suporte e assistência.

d) Problemas com a prestação de serviços: Coordenação de serviços deficitária, funcionários sem o devido preparo e pouco competentes para lidar com as PCD pode afetar a qualidade, acessibilidade e a adequação dos serviços para as PCD.

e) Financiamento inadequado: Os recursos destinados à implementação de políticas e planos geralmente são insuficientes.

f) Falta de acessibilidade: Diversos ambientes, sistemas de transporte (agravante para a não procura por trabalho e impedimento para o acesso a serviços de saúde) e de informação (falta de formatos adequados) não são acessíveis a todos.

g) Falta de consultas e envolvimento: Muitas PCD são excluídas da tomada de decisões em questões que afetarão diretamente suas vidas.

h) Falta de dados e evidências: Conhecer as estatísticas de PCD e suas características pode ajudar na eliminação de barreiras e proporcionar serviços que permitam a participação plena destas pessoas.

Diante dessa realidade, órgãos internacionais como a Organização das Nações Unidas (ONU) e a Organização Internacional do Trabalho (OIT) promulgaram documentos assegurando os direitos básicos universais dessas pessoas. Aprovada em Assembleia Geral da ONU, em 1975, a Declaração dos Direitos das Pessoas Deficientes surgiu como uma referência para assegurar às PCD iguais condições de participação e oportunidades na vida em comunidade. Com as diretrizes vigentes no Brasil a partir de maio de 1991 (Decreto n. 129, 1991), a OIT aprovou em 1983 a Convenção de nº 159 sobre Reabilitação Profissional e Emprego de Pessoas Deficientes, que tem como princípio a igualdade de oportunidades entre os trabalhadores deficientes e os trabalhadores em geral.

No Brasil, conforme divulgado pela Secretaria Nacional de Promoção dos Direitos da Pessoa com Deficiência (Secretaria de Direitos Humanos da Presidência da República, Secretaria Nacional de Promoção dos Direitos da Pessoa com Deficiência, Coordenação-Geral do Sistema de Informações sobre a Pessoa com Deficiência, 2012), 45,6 milhões de pessoas, ou $23,9 \%$ da população, possuem algum tipo de deficiência. As dificuldades encontradas por esses indivíduos, principalmente em questões relacionadas ao trabalho e educação, não diferem daquelas apontadas pelo Relatório Mundial Sobre a Deficiência da OMS (2011). O acesso ao ensino básico é dificultado não só por barreiras arquitetônicas, mas também, pela falta de profissionais de educação preparados para lidar com alunos com deficiências e a falta de recursos assistivos que facilitariam o aprendizado, o que pode ser um fator decisivo para a desistência escolar (Silva \& Carvalho, 2017).

0 primeiro movimento nacional para estabelecer uma igualdade de oportunidades para as PCD no mercado de trabalho se deu na Constituição de 1988 que assegura a "proibição de qualquer discriminação no tocante a salário e critérios de admissão do trabalhador portador de deficiência" (art. 7 parágrafo XXXI da Constituição). Em consonância com a já citada Convenção 159 da OIT, o governo brasileiro aprovou em julho de 1991 a Política Nacional de Cotas, também chamada de "Lei de Cotas", por meio da Lei de n 8.213, que em seu artigo 93 diz que "A empresa com 100 (cem) ou mais empregados está obrigada a preencher de $2 \%$ (dois por cento) a $5 \%$ (cinco por cento) dos seus cargos com beneficiários reabilitados ou pessoas portadoras de deficiência habilitadas". É, porém, em 1999, por meio do Decreto $n^{\circ} 3.298$, que regulamenta a Lei 7.853/89 e dispõe sobre a Política Nacional para a Integração da Pessoa Portadora de Deficiência, que a pes- 


\section{W'INTERACÃO EM PSICOLOGIA}

soa com deficiência recebeu apoio e suporte legais mais amplos de modo a garantir a equiparação de oportunidades no acesso à saúde, educação e trabalho. No âmbito da inclusão da PCD no trabalho formal, destaca-se também a Instrução Normativa da Secretaria de Inspeção do Trabalho-SIT $n^{\circ}$ 98/2012, voltada para a "fiscalização do cumprimento, por parte dos empregadores, das normas destinadas à inclusão no trabalho das pessoas com deficiência e beneficiários da Previdência Social reabilitados".

Apesar de tardias, essas e outras medidas legais são garantidas pela Constituição Brasileira para a plena inserção das PCD no mercado de trabalho formal, oferecendo certa igualdade de oportunidades em relação às pessoas com desenvolvimento típico. Entretanto, apesar dos aparatos legais, o mercado de trabalho brasileiro ainda se mostra resistente à inclusão de PCD. Segundo García (2014) e Monteiro et al. (2011), um dos motivadores deste cenário é a concepção preconceituosa e estereotipada sobre a deficiência estar associada à ideia de dependência e incapacidade. Essa visão de que a PCD é menos produtiva e, portanto, gera menos lucro para a empresa, é pautada em uma série de ideias préconcebidas enraizadas em nossa sociedade, como demonstra o estudo de Carvalho-Freitas e Marques (2009), no qual verificaram que, de acordo com os entrevistados, nem todos os setores são adequados ao emprego de PCD. Suzano et al. (2014) argumentam que essas ideias preconceituosas são fruto de desconhecimento sobre os recursos disponíveis para a plena acessibilidade das PCD ao espaço de trabalho. Além disso, a falta de convivência com as PCD mantém mistificadas as concepções sobre a incapacidade dessas pessoas de alcançar os padrões exigidos pelo mercado. Ainda nesse sentido, Ribeiro e Carneiro (2009) indicam que mesmo para aquelas empresas que buscam se adequar à lei, incorporando PCD em seu quadro de funcionários, existe uma tendência de seletividade nas contratações, uma preferência por PCD que requererão menor adaptação do ambiente de trabalho, consequentemente gerando menor ônus para o empregador. Deste modo, o funcionário é alocado em função da sua deficiência e não de acordo com suas competências profissionais (Monteiro et al., 2011; Tanaka \& Manzini, 2005). Em uma pesquisa junto a uma das Procuradorias Regionais do Trabalho do Ministério Público do Trabalho de Belo Horizonte, Ribeiro e Carneiro (2009) constataram que $63,3 \%$ das PCD empregadas apresentavam, em sua maioria, uma deficiência física de natureza parcial e, destes, cerca de $30 \%$ haviam adquirido a deficiência a partir de acidentes, em maioria, ocorridos dentro da própria empresa. As outras parcelas significativas foram de $25,7 \%$ referentes a pessoas com deficiência auditiva leve e $2,8 \%$ referente a pessoas com deficiência visual.
Aliado ao baixo interesse do empresariado brasileiro em assumir os compromissos estabelecidos por lei, para a inclusão das PCD, está a deficiência de políticas públicas adequadas para a qualificação profissional dessas pessoas, o que torna ainda mais desigual a competição por vagas de emprego junto a pessoas de desenvolvimento típico (Vieira et al., 2015).

\section{A RESPONSABILIDADE SOCIAL E A EMPRESA INCLUSIVA}

Bahia e Schommer (2010) discorrem que o mercado de trabalho tem como compromisso o engajamento no combate ao preconceito e à discriminação a partir da criação de oportunidades de emprego para pessoas com diversas características físicas, sociais e/ou econômicas. Segundo os referidos autores, a empresa inclusiva atua de forma ativa no processo de transformação da sociedade, como um meio que proporciona o desenvolvimento de potencialidades pautadas nas diferenças, seja na contratação ou no oferecimento de produtos e serviços que atendam à necessidade de diferentes pessoas.

$\mathrm{Na}$ integração social, o esforço da adaptação se encontra fundamentalmente no próprio sujeito com deficiência, já que apenas aqueles que se ajustam aos níveis de normalidade do meio social no qual estão inseridos são contratados (Violante \& Leite, 2011). Assis e Carvalho-Freitas (2014) enfatizam o empenho unilateral para superar as barreiras que possam existir, visto que a responsabilidade para a adaptação é do sujeito que se esforça para se aproximar dos padrões sociais vigentes.

Seguindo essa perspectiva, Violante e Leite (2011) destacam a possibilidade dos empregadores considerarem as limitações das PCD ao designarem sua oferta de vagas admitindo apenas aqueles que julgam se enquadrar à determinada função, em outras palavras, não o reconhecem como um sujeito capaz e ativo no processo de produção do âmbito organizacional. Os autores ainda acrescentam que há uma carência em formação de recursos humanos que abordem a inclusão das PCD e a ambientação da empresa para melhor recebê-las no mercado de trabalho, o que é um agravante para o quadro de desemprego e para a visão preconceituosa decorrente dos estereótipos sobre as especificidades, as potencialidades e as limitações das diversas deficiências. A contratação feita de forma inclusiva deveria adaptar a função às especificidades de cada pessoa, de forma a utilizar recursos alternativos e tecnologias auxiliares, se preciso.

Em uma empresa inclusiva, as diferenças de cada sujeito são valorizadas, assim como a realização de modificações internas, sejam elas de caráter físico ou administrativo, para 


\section{H NTERAC̄öEM ET PSICOLOGIA}

Marwin Machay Indio do Brasil do Carmo, Clarissa Garcia Gilla e Patricia Lorena Quiterio que os funcionários com deficiência sejam capazes de exercerem suas funções com qualidade e autonomia.

Segundo Violante e Leite (2011, p.75),

a empresa inclusiva deve promover: a) adaptação dos locais de trabalho; b) adoção de esquemas flexíveis no horário de trabalho; c) revisão das políticas de contratação de pessoal; d) revisão dos programas de treinamento e desenvolvimento de recursos humanos; e) palestras que desmistifiquem a deficiência como incapacitante, dentre outras condições.

A gestão de uma empresa inclusiva é uma tarefa complexa em função dos variados tipos e níveis de deficiência, que podem ocasionar diversos impactos nos modos de adequação das condições e dinâmicas de trabalho (Melo \& Barreira, 2012).

Em adição, há também as barreiras funcionais, que dificultam a inclusão das PCD. Nessa categoria se inclui as arquiteturas inadequadas e a dificuldade de acesso ao local de trabalho e ao meio de transporte. Há uma elevada parcela de PCD que possui baixa escolaridade, logo, encontrar sujeitos com qualificação para ocuparem cargos com mais reconhecimento e prestígio social também é um obstáculo. A maioria tende a ocupar empregos de baixo rendimento. É dever da sociedade eliminar essas barreiras para que todos possam ter acesso aos serviços, lugares, informações e bens necessários ao seu desenvolvimento pessoal, social, educacional e profissional (Assis \& Carvalho-Freitas, 2014). A sociedade inclusiva legitima as necessidades de cada indivíduo e assegura mesmo com suas especificidades que todos tenham a possibilidade de acesso à cultura, ao trabalho, à comunicação e a todos os campos de desenvolvimento sociais (Melo \& Barreira, 2012). É dever da sociedade se adaptar para incluir todas as demandas populacionais que se encontram em exclusão, em contrapartida da ideologia da integração na qual o próprio indivíduo deve se moldar ao meio social (Violante \& Leite, 2011).

A inclusão social é responsabilidade de todos e quando encarada como um compromisso social permite que condições mais igualitárias sejam promovidas, sejam elas estruturais, sociais ou econômicas, a fim de viabilizar que todos os indivíduos exerçam seus direitos e obrigações de cidadãos (Glat \& Pletsch, 2012). Encarar o sujeito com deficiência como um ser capaz, produtivo, autônomo e dotado de qualificação profissional é um exercício lento que permite o reconhecimento social desse sujeito enquanto pertencente às posições de trabalho digno (Violante \& Leite, 2011). Cabe à sociedade mudar suas concepções naturalizadas de limitações referentes às PCD e enxergá-los sem estranhamento como atuantes em uma posição de trabalho digno, além de prover as adaptações necessárias no suprimento às deman- das de toda e qualquer pessoa (Neves-Silva et al., 2015; Passerino \& Pereira, 2014; Violante \& Leite, 2011).

Logo, devido ao cenário nacional (adequação das empresas à implementação da lei, adaptações arquitetônicas e atitudinais $\mathrm{e}$, aos aspectos interpessoais envolvidos no processo de inclusão), constata-se a importância da continuidade de estudos que enriqueçam a discussão das PCD no mercado de trabalho ampliando as reflexões e (re)pensando as estratégias de inclusão. Neste sentido, este debate se faz necessário no campo da Psicologia, em seus diferentes espaços de atuação, tanto em nível de formação inicial quanto continuada. 0 psicólogo tem um papel fundamental como profissional que promove senso crítico e elabora coletivamente ações para a inclusão das PCD no mercado de trabaIho e, especialmente na sociedade.

Com base no exposto, o objetivo deste trabalho foi investigar o processo da inclusão das PCD no mercado de trabalho brasileiro averiguando os motivos do envolvimento de empresas na contratação destas pessoas; o perfil dos funcionários e o processo de contratação; o acompanhamento das PCD no cotidiano da empresa e sua relação com os outros funcionários.

\section{MÉTODO}

\section{PROCEDIMENTOS}

A pesquisa pelas empresas foi realizada por meio da página http://www.deficienteonline.com.br, que reúne anúncios de vagas de emprego para profissionais com deficiência. No campo "Nossos Clientes", disponível na página, encontraramse 327 empresas que já utilizaram o serviço de anúncio da página e, dentre elas, selecionamos 162 empresas (cerca de metade da totalidade) de forma aleatória para o envio do questionário. Destas, 29 responderam ao contato inicial, porém, mesmo após o reenvio da solicitação, apenas 04 empresas concordaram em participar da pesquisa.

O contato com cada empresa foi realizado virtualmente, por meio do envio de mensagem no campo de contato diretamente na página das empresas selecionadas ou por meio de mensagens por e-mail para o setor responsável pela comunicação. Nesse primeiro contato, apresentou-se a proposta do artigo para as empresas pedindo a colaboração destas em responder algumas perguntas por meio de questionário - a ser apresentado na sessão de instrumentos - sobre a aplicação da Lei de Cotas, bem como sobre o processo de seleção das PCD e, finalmente, sobre como estas pessoas estão inseridas no corpo de funcionários. Na mensagem foi pedido um prazo, de preferência, de sete dias para o retorno das informações. 


\section{N"INTERACÃO EM PSICOLOGIA}

\section{PARTICIPANTES}

As quatro empresas participantes da pesquisa pertencem ao setor privado e atuam em diferentes ramos de atividade, bem como se localizam em diferentes regiões do país. A Tabela 1 apresenta um resumo com as características gerais das empresas.
Observa-se que o perfil dos setores respondentes é variado. Em relação ao ano de fundação das empresas, constatase que três empresas iniciaram suas atividades antes da Lei de Cotas (1991). Uma empresa iniciou suas atividades contratando PCD desde a sua fundação.

Tabela 1. Caracterização geral das empresas participantes

\begin{tabular}{cccccc}
\hline Empresas & Ramo de Atividade & Localização & $\begin{array}{c}\text { Ano de } \\
\text { fundação }\end{array}$ & $\begin{array}{c}\text { Ano de } \\
\text { contratação } \\
\text { de PCD }\end{array}$ & Setor respondente \\
\hline A & Livros e papelaria & $\begin{array}{c}\text { Paraná, Santa } \\
\text { Catarina e São } \\
\text { Paulo }\end{array}$ & 1963 & 2011 & Analista de RH \\
B & $\begin{array}{c}\text { Aluguel de } \\
\text { aparelhos } \\
\text { eletroeletrônicos }\end{array}$ & $\begin{array}{c}\text { Multinacional } \\
\text { (Centro-oeste, } \\
\text { Nordeste e } \\
\text { Sudeste) }\end{array}$ & 1973 & 2011 & $\begin{array}{c}\text { Comunicação e } \\
\text { Marketing }\end{array}$ \\
C & $\begin{array}{c}\text { Centro Hospitalar } \\
\text { D }\end{array}$ & Salvador, BA & 1994 & 1994 & $\begin{array}{c}\text { Equipe do Serviço } \\
\text { Desenvolvimento de } \\
\text { Pessoas }\end{array}$ \\
& Banco privado & Multinacional & & D & Banco privado \\
\hline
\end{tabular}

\section{INSTRUMENTOS}

Com vista a caracterizar o modo de ação de empresas brasileiras com as PCD, foi elaborado pelos autores um questionário estruturado, com base no referencial teórico deste estudo, contendo sete perguntas abertas que investigavam temas relacionados à inclusão de PCD no mercado de trabaIho, conforme apresenta a Tabela 2.

\section{Tabela 2. Questionário estruturado enviado às empresas}

1) Por que a empresa se envolveu nessa
proposta de contratação de pessoas com
deficiência?
2) Quantos funcionários foram contratados
com deficiência?
3) Quais são estas deficiências?
4) Desde quando iniciaram na empresa?
5) Como é feito o acompanhamento dessas
pessoas no dia-a-dia?
6) Como foi a seleção de vaga?
7) Como é a relação desses funcionários com
o grupo?

\section{ANÁLISE DOS DADOS}

A análise das respostas do questionário realizado junto aos profissionais das empresas entrevistadas baseou-se na análise de conteúdo e possibilitou reflexões e argumentações propostas no estudo. De modo geral, define-se a análise de conteúdo como um conjunto de procedimentos metodológicos que visa convergir a objetividade e a subjetividade, por meio da interpretação baseada na inferência (Bardin, 1977/2010; Castro et al., 2011).

O levantamento do conteúdo das respostas permitiu a categorização dos itens do questionário por meio de quatro eixos temáticos, sendo: 1) Envolvimento da empresa na proposta de contratação de PCD; 2) Contratação das PCD pela empresa (características dos funcionários e o processo de contratação); 3) Acompanhamento das PCD no cotidiano da empresa e, 4) Relação das PCD com os outros funcionários.

0 Eixo 1 apresenta dados relacionados à motivação das empresas para a contratação de PCD e ao período no qual passaram a se engajar nessa iniciativa. Já o Eixo 2 engloba um dos objetivos da pesquisa ao investigar se as empresas entrevistadas cumprem a cota mínima de inserção de PCD exigida por lei. Também se, porventura, excedem esta cota, 
ou caso não tenham atingido o mínimo necessário, o quão distante está da reserva obrigatória. O Eixo 3 relata quais ações a empresa realiza para acompanhar os funcionários nas atividades habituais do trabalho. E, por fim, o Eixo 4 aborda os aspectos interpessoais entre os funcionários com e sem deficiência.

\section{RESULTADOS E DISCUSSÃO}

Os resultados dessa pesquisa foram organizados, a partir da análise de conteúdo, em Eixos Temáticos. Seguem as informações provenientes das análises realizadas.

\section{EIXO 1: ENVOLVIMENTO DA EMPRESA NA PROPOSTA DE CON- TRATAÇÃO DE PCD}

No que se refere à contratação de $P C D$, a empresa $A$ afirma que se envolveu nessa proposta "para promover a diversidade, troca de experiências entre os colaboradores do grupo e o cumprimento da cota". A empresa B segue uma linha de pensamento parecida no tocante à promoção da diversidade ao afirmar que o motivo para a contratação de PCD foi "fazer a diferença, eliminando o preconceito e reconhecendo a igualdade social". A empresa $C$ também cita como motivação o cumprimento da cota e acrescenta crer na "importância de promovermos oportunidade de emprego para uma parcela de profissionais [...] que devido a algumas limitações têm dificuldade de colocação no mercado de trabalho". Por fim, a organização $D$ também cita como motivação a responsabilidade social da empresa de participar ativamente na inclusão do profissional com deficiência. Além disto, menciona o cumprimento da cota de $5 \%$ de funcionários com deficiência, embora ressalte que já empregasse PCD desde a década de 1980, cerca de dez anos antes da aprovação da Política Nacional de Cotas no Brasil. Esta ocorre em um período relativamente próximo à aprovação da Declaração dos Direitos das Pessoas com Deficiência pela ONU, em 1975, que é quando os direitos das PCD ganharam maior visibilidade (Assis \& Carvalho-Freitas, 2014). Este mesmo encaminhamento não foi adotado pelas Empresas $A$ e $B$, que foram fundadas no período da declaração acima, mas iniciaram a contratação de PCD somente após a Lei de Cotas.

$O$ argumento de maior prevalência é do cumprimento da Lei de Cotas, citado pelas empresas A, C e D. Segundo Vieira et. al (2015), acredita-se que muitas empresas contratem PCD apenas para evitar as consequências legais do descumprimento da lei e, deste modo, acabam por dar preferência àqueles com os menores graus de limitação. Em seguida, citados duas vezes cada, estão os argumentos de Promoção da Diversidade (A e B) e Inclusão Profissional das PCD (C e D). Ambas justificativas sugerem um desejo de ir além da simples adequação à lei, mas um anseio das empresas em servir como uma plataforma de integração das PCD com o cotidiano social.

\section{EIXO 2: CONTRATAÇÃO DAS PCD PELA EMPRESA}

O artigo 36 mencionado no Decreto $n^{\circ} 3.298$, estabelece que empresas com até 200 funcionários devem ter $2 \%$ do quadro de empregados ocupados por PCD; com números entre 201 e $500,3 \%$; entre 501 e $1.000,4 \%$; e empresas que possuam acima de 1.001 funcionários, $5 \%$.

Em relação às PCD contratadas pelas empresas entrevistadas, a Tabela 3 apresenta o número de funcionários atualmente integrados na equipe.

Tabela 3. Resposta ao item 2 - Quantos funcionários foram contratados com deficiência?

\begin{tabular}{ccccc}
\hline Empresa & $\begin{array}{c}\text { Número de } \\
\text { funcionários }\end{array}$ & $\begin{array}{c}\text { Número de PCD } \\
\text { contratadas }\end{array}$ & $\begin{array}{c}\text { Percentual de } \\
\text { PCD contratadas } \\
(\%)\end{array}$ & $\begin{array}{c}\text { Percentual de } \\
\text { contratações de PCD } \\
\text { exigido pela lei (\%) }\end{array}$ \\
\hline A & $1200^{\mathrm{a}}$ & 36 & 3,0 & 5,0 \\
B & $259^{\mathrm{b}}$ & 9 & 3,5 & 2,0 \\
C & $1591^{\mathrm{c}}$ & 48 & 3,0 & 5,0 \\
D & $90320^{\mathrm{d}}$ & 3947 & 4,4 & 5,0 \\
\hline
\end{tabular}

Nota. a,c,d Fonte: Informações obtidas no website das empresas. Acesso em: 01 de novembro de 2017.

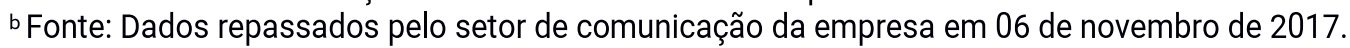

A empresa A lista como uma de suas motivações o cumprimento da cota estabelecida por lei, no entanto está aquém do mínimo recomendado pela legislação, com 3,0\% de seus cargos ocupados por PCD. Uma situação semelhante ocorre com a empresa $C$, que possui 1.591 funcionários, sendo ape- nas 3,0\% destes PCD. Ao ser questionada do porquê de se envolver na contratação de PCD, a empresa $D$ afirma: "atingimos a representatividade de $5 \%$ de nosso quadro de ativos, em virtude de uma ampla movimentação pelo cumprimento da cota governamental”. Entretanto, segundo dados repassados pela 


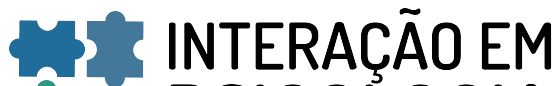 PSICOLOGIA}

Comunicação Corporativa, a empresa tem reservado $4,4 \%$ de vagas para PCD. Por fim, somente a empresa $B$ atende ao exigido por lei com $3,5 \%$ de PCD em seu corpo de funcionários.

Esta pesquisa também buscou dados sobre uma possível preferência dos empregadores para PCD com determinado tipo de deficiência. Conforme indica Suzano et. al (2014), o mercado de trabalho brasileiro tende a absorver PCD que requerem menores esforços por parte do empregador para a adaptação do funcionário ao ambiente e à função. 0 que, segundo dados levantados pelos autores, reflete em um alto percentual de deficientes físicos e auditivos empregados em detrimento de outros tipos de deficiência.

A Tabela 4 destaca os tipos de deficiência no corpo de funcionários das empresas entrevistadas. Os dados indicam a presença ou a ausência de determinado tipo de deficiência, já que no questionário o item englobou apenas quais os tipos de deficiência eram encontradas dentre seus funcionários e não quantos funcionários apresentavam tal deficiência.

\section{Tabela 4. Ocorrência dos tipos de deficiência nos funcionários das quatro empresas}

\begin{tabular}{lcc}
\hline \multicolumn{1}{c}{ Categoria } & $\mathrm{N}$ & $\%$ \\
\hline Física & 4 & 100 \\
Visual & 4 & 100 \\
Auditiva & 3 & 75 \\
Reabilitado & 1 & 25 \\
Lesão Medular & 1 & 25 \\
Paralisia Cerebral & 1 & 25 \\
Intelectual & 1 & 25 \\
Múltipla & 1 & 25 \\
\hline
\end{tabular}

Os dados indicam que os maiores índices são de deficiência física e visual, seguidos da deficiência auditiva. Enquanto que os reabilitados, com lesão medular, paralisia cerebral, deficiência intelectual e deficiência múltipla são citados apenas uma vez cada dentre as quatro respostas obtidas.

Estes achados corroboram com o estudo de Ribeiro e Carneiro (2009) que constataram uma tendência de contratação de pessoas com deficiência física, auditiva e visual e, que esta seletividade pode ter relação com as adaptações necessárias no ambiente de trabalho, sejam no arranjo do espaço, sejam no uso de tecnologias assistivas ou nas questões interpessoais, pois parece que as demais deficiências exigiriam maiores adaptações no espaço físico, nos aspectos atitudinais e no acompanhamento das atividades realizadas pela PCD.
Quanto ao processo de seleção de vagas para PCD as empresas $A, C$ e $D$ informaram que a seleção de vagas é conduzida por um setor interno de recursos humanos. A empresa C destaca que há processos de seleção diferenciados por meio do auxílio de empresas parceiras especializadas.

A empresa A responde que possui programa constante de captação de talentos com deficiência e acrescenta "essas pessoas são avaliadas visando o entendimento da necessidade especial do candidato e a possibilidade de encaixá-lo em oportunidades disponíveis, estas podem ser em qualquer setor dependendo da deficiência do candidato". Nota-se que no programa de captação de talentos com deficiência, as PCD são escolhidas ou direcionadas a ocupar uma função na qual possa se desenvolver com maior eficiência, isto é, a empresa ressalta que a alocação do funcionário em determinado cargo está condicionada à sua deficiência. De modo semelhante, a empresa $B$ responde "Levamos em consideração se a deficiência é um fator que compromete as exigências de execução do cargo, ou seja, se estão aptos a realizar tal tarefa". O porta voz da B finaliza sua resposta dizendo que "a pessoa com deficiência é como qualquer outro candidato, só precisa ser respeitada de acordo com suas limitações".

Violante e Leite (2011) observaram essa tendência em seu estudo sobre a concepção de empregadores sobre as PCD ao identificarem que na maior parte das falas dos entrevistados ainda predomina a ideia de limitação exclusivamente pessoal e a ideia de falta nas PCD. Os autores ressaltam que tais empregadores ainda concebem a deficiência como uma incapacidade, de modo que os obstáculos são gerados pela condição das PCD e não pelas condições do ambiente.

As análises sugerem um repensar sobre a parceria entre empresa e PCD à medida que, em uma proposta colaborativa, ambos os membros da díade precisam se envolver com a proposta de uma empresa inclusiva, visto que as empresas possuem responsabilidades na seleção, contratação, adequação dos espaços e debates sobre a inclusão e ao mesmo tempo, as PCD precisam fazer parte destes espaços de reflexão e discussão de forma participativa promovendo um cenário inclusivo.

\section{EIXO 3: ACOMPANHAMENTO DAS PCD NO COTIDIANO DA EM- PRESA}

No que se refere ao acompanhamento de PCD no cotidiano de trabalho, a empresa A tem o gestor como principal recurso. Em contrapartida, as demais empresas articulam a função do gestor com outros setores como a consultoria interna do setor de recursos humanos, uma área de diversidade e a parceria com a Medicina e Segurança do trabalho. 
Tanto a empresa $\mathrm{B}$ quanto $\mathrm{C}$ demonstraram uma preocupação com a adaptação do posto de trabalho para uma meIhor integração da PCD. A empresa B relata "nos preocupamos e damos maior atenção nas atividades que possam apresentar dificuldades de execução adaptando às suas necessidades, sempre verificamos como os mesmos estão se sentindo com o trabalho e sempre atentos a questões de acompanhamentos médicos". De modo semelhante, a empresa $\mathrm{C}$ responde "a consultoria interna do $\mathrm{RH}$ junto ao gestor faz o acompanhamento. Inclusive, com a parceria da Medicina e Segurança do Trabalho, no caso de necessidade de adaptação do profissional no posto de trabalho".

\section{EIXO 4: RELAÇÃO DAS PCD COM OS OUTROS FUNCIONÁRIOS}

Ao serem questionados sobre a relação da PCD com os demais funcionários, todos os entrevistados constataram haver facilidade na ambientação. Em adição, as empresas recorrem ao setor de recursos humanos ou aos gestores para mediarem o acolhimento dos funcionários, caso necessário.

A empresa A conta que nem sempre as PCD se adaptam à função e há funcionários que optam por deixar o emprego durante o período de experiência. Mais uma vez, predomina a ideia de que a PCD é quem deve se adaptar às exigências do ambiente. Cabe indagarmos a partir dessa fala se o que tem afastado esses funcionários tão precocemente do emprego seja justamente a falha da própria empresa em oferecer condições para o pleno desenvolvimento da capacidade da PCD, visto que, conforme argumenta Neves-Silva, Prais e Silveira (2015), a acessibilidade é imprescindível para a inclusão das PCD, pois quando são privados das adaptações necessárias, a tendência é que experimentem abandono e uma maior dificuldade de relacionamento com os outros trabalhadores. $\mathrm{Ou}$, além disso, se por uma atitude discriminatória, esses funcionários estejam sendo direcionados a funções para as quais não estão aptos ou confortáveis, apenas por estas serem consideradas mais adequadas à sua deficiência. Em uma pesquisa com gestores e alunos de especialização em administração, Carvalho-Freitas e Marques (2009) verificaram que $20 \%$ dos gestores e $89 \%$ dos alunos de especialização entrevistados consideram que determinados setores não são adequados ao emprego de $\mathrm{PCD}$, pois tais funcionários estariam mais suscetíveis a acidentes e a ter problemas de relacionamento com os demais, além da possibilidade de assumirem atitudes inadequadas na empresa. Por este motivo é importante que a empresa dialogue com a PCD, de modo a identificar e buscar soluções para possíveis situações de desajuste, visto que o direcionamento inadequado das PCD acaba por reforçar o estereótipo de inadequação desta ao trabalho.

0 porta voz da empresa A complementa sua resposta frisando que, no entanto, muitos permanecem e se sentem am- bientados, e que no setor de estoque há uma grande quantidade de deficientes auditivos guiados por um gestor que se comunica com estes funcionários por meio de Libras (língua brasileira de sinais).

A inclusão deve ocorrer por meio de um diálogo entre empregador e funcionário, a fim de que o trabalhador com deficiência seja incluído no processo de tomada de decisão, como figura participativa. De outro modo, o empregador se torna o condutor da escolha, por vezes, direcionando o funcionário para uma determinada atribuição em função da especificidade de sua deficiência. 0 processo de inclusão prescinde de uma suspensão de conceitos pré-definidos sobre normalidade e um empenho em empregar adaptações necessárias no ambiente e nos modos de trabalho, de forma que sejam estabelecidas condições únicas que atendam a cada individualidade, bem como as demandas do coletivo (Monteiro et. al., 2011; Tanaka \& Manzini, 2005).

A resposta da empresa $B$ também suscita alguns questionamentos sobre a concepção de normalidade e deficiência adotada pela empresa. Afirmam que "não há distinção nas relações ou qualquer forma diferenciada de tratamento, [...] em alguns casos, quando a deficiência não é visível, alguns funcionários nem tem conhecimento da necessidade especial do indivíduo." Ao declarar que não fazem distinção e que deficiências não visíveis passam despercebidas, a B demonstra que mesmo um discurso para enaltecer as qualidades dos trabalhadores com deficiência ainda carrega uma ideia de dicotomia entre o normal e o deficiente. Ou seja, existe o grupo de funcionários normais e aqueles aos quais falta algo, que estariam em desvantagem em relação ao primeiro. Segundo García (2014) e Monteiro et al. (2011) essa visão estereotipada das PCD encobre o seu verdadeiro potencial e acaba por valorizar sua competência quando esta consegue se igualar ou superar àquela do grupo considerado normal.

A lacuna no conhecimento sobre deficiência na formação e sensibilização de funcionários e gestores contribui para um cenário com poucas possibilidades de crescimento profissional para essa população. Há vantagem em um estilo de gestão cujos objetivos profissionais, prioridades e valores organizacionais possam ser apresentados com clareza de forma a oferecer amparo e motivação para às PCD contratadas (Assis \& Carvalho-Freitas, 2014). O preconceito, a atuação de gestões de forma despreparada e a baixa escolarização das PCD têm como consequência a baixa taxa dessas pessoas em funções mais prestigiadas, inclusive como a de gestores. Assis e Carvalho-Freitas (2014) sugerem que empresas se atentem a alguns aspectos para serem bem-sucedidas na inclusão social, como: a acessibilidade; o investimento em qualificação profissional das PCD; o diálogo sobre os critérios de crescimento na instituição; e a adoção 


\section{W'INTERACÃO EM PSICOLOGIA}

de programas de ambientação como a implementação de tutores e a realização de eventos de socialização como reuniões e rodas de conversa.

\section{CONSIDERAÇÕES FINAIS}

A luta por uma sociedade inclusiva gerou resultados na legislação brasileira como a Lei das Cotas. A partir desse cenário, o trabalho formal se torna uma possibilidade favorável para esses sujeitos e com isso pode proporcionar aprendizagem, desenvolvimento e independência financeira (Melo \& Barreira, 2012).

Apesar dos avanços, as PCD ainda se deparam com dificuldades de segregação e exclusão social pautadas por preconceitos (Glat \& Pletsch, 2012). Conforme demonstrado por Suzano et. al (2014), a falsa ideia de incapacidade vinculada à deficiência, a insistência em selecionar algumas categorias de deficiências ou certos níveis de comprometimento, são fontes de resistência para o ingresso no âmbito profissional. Em adição, as PCD precisam lidar com uma série de barreiras de acessibilidade, como as funcionais, as atitudinais e as arquitetônicas (Assis \& Carvalho-Freitas, 2014).

Assis e Carvalho-Freitas (2014) destacam que o Brasil possui um aparato legal avançado em comparação ao cenário mundial de assistência às $P C D$, entretanto, falta eficácia no cumprimento das leis e normas já existentes. Ribeiro e Carneiro (2009) discutem que esta contratação, que visa apenas o cumprimento da lei é realizada de forma seletiva. Um ambiente adverso para este indivíduo, cujas adaptações e adequações sejam ignoradas, pode comprometer sua permanência nesse ambiente de trabalho (Garcia, 2014; Neves-Silva et al., 2015). Em complementariedade a esta discussão, Assis e Carvalho-Freitas (2014) destacam que a convivência com PCD proporciona aprendizado, reduz o preconceito e promove a valorização profissional dos funcionários. Deste modo, sendo a empresa parte do âmbito social tem, portanto, seu dever na promoção de uma sociedade inclusiva a fim de combater o preconceito e a discriminação.

Este estudo contribui com as pesquisas sobre o panorama do emprego de PCD no mercado de trabalho brasileiro ao investigar as motivações para a contratação e de que modo estes funcionários são inseridos no cotidiano das empresas. Corroborando com outras pesquisas no mesmo tema (CarvaIho-Freitas \& Marques, 2009; Monteiro et al., 2011; Ribeiro \& Carneiro, 2009; Tanaka \& Manzini, 2005), o presente estudo identificou em relação: i) ao envolvimento da empresa na proposta de contratação das PCD que a prioridade é o cumprimento da Lei de Cotas, seguida pela responsabilidade de inclusão social; ii) a contratação das PCD pela empresa identificou que um quarto das empresas entrevistadas atende a cota estabelecida pela legislação. Destaca-se que há uma tendência em contratar PCD que exijam menores adaptações no ambiente de trabalho, bem como se faz necessário incluir o funcionário neste debate de inclusão das PCD nas diversas tarefas da empresa; iii) ao acompanhamento das PCD no cotidiano da empresa que ocorre uma assistência na execução das atividades e; iv) ao relacionamento das PCD com os outros funcionários há facilidade na ambientação e necessidade de conhecimento sobre as deficiências.

De início, se constatou que os funcionários com deficiência ainda ocupam uma parcela muito próxima ao mínimo requerido, o que pode indicar uma falta de confiança na capacidade produtiva das PCD. Essa desconfiança se reflete na forma como essas pessoas são direcionadas aos postos de trabalho, visto que, conforme algumas respostas evidenciaram, persiste a concepção sobre a limitação das PCD, que as colocam em desvantagem com os demais funcionários e restringe suas potencialidades.

Adotar um novo olhar no processo de recrutamento para a inclusão no mercado de trabalho contribui para que as PCD possam desenvolver suas potencialidades (Instituto Ethos de Empresas e Responsabilidade Social, 2002). Um ambiente adequado para atender às necessidades individuais de cada funcionário com deficiência é um passo fundamental no processo de inclusão. Sugere-se que as empresas estejam a par das soluções em Tecnologias Assistivas, que compõe um conjunto de instrumentos destinados a compensar a impossibilidade da resolução de determinado problema ampliando as habilidades funcionais (Passerino \& Pereira, 2014).

Embora os achados deste estudo não sejam representativos da totalidade das empresas nacionais, trazem evidências empíricas, recentes e relevantes sobre a realidade destas organizações que contribuem para uma reflexão-ação sobre a temática da inclusão das PCD. Eles indicam a necessidade de diálogo entre os atores do processo de inclusão, ressaltando-se a importância da parceria entre os gestores e a equipe, com a finalidade de discutir as concepções e o plano de ação. 0 psicólogo apresenta-se como elemento fundamental neste processo, tanto em relação ao preenchimento da lacuna sobre a falta de informação sobre as deficiências, bem como na promoção de estratégias de inclusão. Para futuras investigações, recomenda-se que o contato com as empresas seja feito por meios além do virtual, de forma que a proximidade na relação entre pesquisador e pesquisado seja um motivador para a participação destes na pesquisa. Também, sugere-se que sejam realizadas pesquisas em âmbito regional e que tais resultados sejam comparados com uma perspectiva nacional, de modo a compreender se as conclusões aqui relatadas se estendem a todo o território do país ou se se circunscrevem a determinadas regiões. 


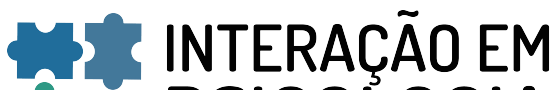 PSICOLOGIA}

O senso de valorização, inclusão e independência de um sujeito na sociedade capitalista está fortemente relacionado à sua capacidade laboral. Ao deslegitimar PCD como agentes ativos de produção e excluí-las do meio social, consequentemente a noção de normalidade de todos os indivíduos se torna distorcida sobre as capacidades e às limitações de cada sujeito (Assis \& Carvalho-Freitas, 2014). Permitir que as PCD exerçam seus direitos e sua cidadania por meio da inclusão no mercado de trabalho possibilita a mudança de perspectiva de todos os envolvidos, inclusive dos próprios sujeitos com deficiência que passam a se enxergar como agentes ativos da sociedade em que vivem, além de presenciarem a mudança do olhar discriminatório das pessoas em sua volta. Por fim, a adoção das práticas inclusivas nas empresas caracteriza parte de um processo maior, cujo objetivo é a valorização da diversidade e dos diferentes potenciais de cada indivíduo no âmbito social.

\section{DECLARAÇÃO DA CONTRIBUIÇÃO DOS AUTORES}

M.M.I.B.C., C.G.G. e P.L.Q. contribuíram para a conceitualização, investigação, visualização do artigo e formulação da metodologia; M.M.I.B.C. e C.G.G. são também responsáveis pela redação inicial (rascunho) pela redação final (revisão e edição); P.L.Q. foi responsável pela administração do projeto e pela supervisão e liderança das atividades de planejamento e execução da pesquisa, além de participar também nas etapas de revisão e edição do manuscrito.

\section{DECLARAÇÃO DE CONFLITOS DE INTERESSE}

Os autores declaram que não há conflitos de interesse no manuscrito submetido.

\section{REFERÊNCIAS}

Assis, A. M., \& Carvalho-Freitas, M. N. (2014). Estudo de caso sobre a inserção de pessoas com deficiência numa organização de grande porte. Revista Eletrônica de Administração, 20(2), 496-528. https://doi.org/ 10.1590/1413-2311022201342126

Bahia, M. S., \& Schommer, P. C. (2010). Inserção profissional de pessoas com deficiência nas empresas: Responsabilidades, práticas e caminhos. Organizações \& Sociedade, 17(54). 92302010000300003

Bardin, L. (2010). Análise de Conteúdo. Edições 70 (Trabalho original publicado em 1977).

Carvalho-Freitas, M. N. \& Marques, A. L. (2009). Pessoas com deficiência e trabalho: Percepção de gerentes e pós-graduandos em administração. Psicologia Ciência e Profis- são, 29(2), 244-257. https://doi.org/10.1590/ s1414-98932009000200004

Castro, T. G., Abs, D., \& Sarriera, J. C. (2011). Análise de conteúdo em pesquisas de psicologia. Psicologia: Ciência e Profissão, 31(4), 814-825. https://doi.org/10.1590/S141498932011000400011.

Constituição da República Federativa do Brasil de 1988. http:// www.planalto.gov.br/ccivil_03/Constituicao/Constituicao.htm

Decreto n. 129, de 22 de maio de 1991. Promulga a Convenção $n^{\circ} 159$, da Organização Internacional do Trabalho OIT, sobre Reabilitação Profissional e Emprego de Pessoas Deficientes. http://www.planalto.gov.br/ccivil_03/decreto/1990-1994/d0129.htm

Decreto n. 3.956, de 8 de outubro de 2001. Promulga a Convenção Interamericana para a Eliminação de Todas as Formas de Discriminação contra as Pessoas Portadoras de Deficiência. http://www.planalto.gov.br/ccivil_03/decreto/2001/d3956.htm

Decreto-Lei n. 3.298, de 20 de dezembro de 1999. Regulamenta a Lei no 7.853, de 24 de outubro de 1989, dispõe sobre a Política Nacional para a Integração da Pessoa Portadora de Deficiência, consolida as normas de proteção, e dá outras providências. https://www2.camara.leg.br/ legin/fed/decret/1999/decreto-3298-20-dezembro-1999367725-norma-pe.html

García, V. G. (2014). Panorama da inclusão das pessoas com deficiência no mercado de trabalho no Brasil. Trabalho, Educação e Saúde, 12(1), 165-187. https://doi.org/ 10.1590/s1981-77462014000100010

Glat, R., \& Pletsch, M. D. (2012). Inclusão escolar de alunos com necessidades especiais (2a ed.). EdUERJ.

Instituto Ethos de Empresas e Responsabilidade Social. (2002). 0 que as Empresas podem fazer pela Inclusão das Pessoas com Deficiência. https://www3.ethos.org.br/wpcontent/uploads/2012/12/25.pdf

Instrução Normativa n. 98, de 15 de agosto de 2012. Dispõe sobre procedimentos de fiscalização do cumprimento, por parte dos empregadores, das normas destinadas à inclusão no trabalho das pessoas com deficiência e beneficiários da Previdência Social reabilitados. http:// www.anamt.org.br/site/upload_arquivos/legislacao_-_instrucoes_normativas_2012_181220131710287055475.pdf

Lei n. 8.213, de 24 de julho de 1991. Dispõe sobre os Planos de Benefícios da Previdência Social e dá outras providências. http://www.planalto.gov.br/ccivil_03/leis/L8213cons.htm

Melo, T. T., \& Barreira, H. S. (2012). Inclusão e gestão da pessoa com deficiência no mercado de trabalho. https://laboratoriodeinclusao.files.wordpress.com/2012/12/ inclusc3a3o-e-gestc3a3o-de-pcd-no-mercado-de-trabaIho.pdf 


\section{-4: INTERACÃO EM IF PSICOLOGIA}

Monteiro, L. G., Oliveira, S. M. Q., Rodrigues, S M. \& Dias, C. A. (2011). Responsabilidade social empresarial: inclusão de pessoas com deficiência no mercado de trabalho. Revista Brasileira de Educação Especial, 17(3), 459-480. https:// doi.org/10.1590/S1413-65382011000300008

Neves-Silva, P., Prais, F. G. \& Silveira, A. M. (2015). Inclusão da pessoa com deficiência no mercado de trabalho em Belo Horizonte, Brasil: cenário e perspectiva. Ciência \& Saúde Coletiva, 20(8), 2549-2558. https://doi.org/10.1590/141381232015208.17802014

Organização das Nações Unidas. (1975). Declaração dos direitos das pessoas deficientes. http://portal.mec.gov.br/ seesp/arquivos/pdf/dec_def.pdf

Organização Mundial da Saúde. (2011). Relatório Mundial Sobre a Deficiência. Governo do Estado de São Paulo - Secretaria dos Direitos da Pessoa com Deficiência. http:// www.pessoacomdeficiencia.sp.gov.br/usr/share/documents/Relatorio_Mundial_SUMARIO_PDF2012.pdf

Passerino, L. e Pereira, A. (2014). Educação, inclusão e trabaIho: Um debate necessário [Sessão temática: Educação especial]. Educação \& Realidade, 39(3), 831 -846. https:// doi.org/10.1590/S2175-62362014000300011

Ribeiro, M. A., \& Carneiro, R. (2009). A inclusão indesejada: As empresas brasileiras face à lei de cotas para pessoas com deficiência no mercado de trabalho. Organizações \& Sociedade, 16(50), 545-564. https://doi.org/10.1590/ S1984-92302009000300008

Silva, N. C., \& Carvalho, B. G. E. (2017). Compreendendo o processo de inclusão escolar no Brasil na perspectiva dos professores: Uma revisão integrativa. Revista Brasileira de Educação Especial, 23(2), 293-308. https://doi.org/ $10.1590 / \mathrm{s} 1413-65382317000200010$

Secretaria de Direitos Humanos da Presidência da República, Secretaria Nacional de Promoção dos Direitos da Pessoa com Deficiência, Coordenação-Geral do Sistema de Informações sobre a Pessoa com Deficiência. (2012). Cartilha do Censo 2010 - Pessoas com Deficiência. www.pessoacomdeficiencia.gov.br
Suzano, J. C. C., Carvalho-Freitas, M. N., Tette, R. P. G., Brighenti, C. R. G. B., \& Vieira-Silva, M. (2014). A percepção dos gestores acerca do desempenho de trabalhadores com diferentes tipos de deficiência. Interação em Psicologia, 18(3), 239-250. http://dx.doi.org/10.5380/ psi.v18i3.35498

Tanaka, E. D. O. \& Manzini, E. J. (2005). O que os empregadores pensam sobre o trabalho da pessoa com deficiência? Revista Brasileira de Educação Especial, 11(2), 273-294. https://doi.org/10.1590/S1413-65382005000200008

Vieira, C. M., Vieira, P. M. \& Francischetti, I. (2015). Profissionalização de pessoas com deficiência: Reflexões e possíveis contribuições da psicologia. Revista Psicologia: Organizações e Trabalho, 15(4), 352-361.

Violante, R. \& Leite, L. (2011). A empregabilidade das pessoas com deficiência: uma análise da inclusão social no mercado de trabalho do município de Bauru, SP. Cadernos de Psicologia Social do Trabalho, 14(1), 73-91. https://doi.org/ 10.11606/issn.1981-0490.v14i1p73-91

World Health Organization. (2003). World Health Survey. Geneva: World Health Organization. Recuperado de: https:// www.who.int/healthinfo/survey/en/

World Health Organization. (2008). The Global Burden of Disease: 2004 Update. https://www.who.int/healthinfo/global_burden_disease/GBD_report_2004update_full.pdf? ua $=1$.
Data de submissão: 15/06/2018 Primeira decisão editorial: 07/01/2019 Aceite em 22/04/2019 